\title{
STRATEGY SPACE EXPLORATION OF A MULTI-AGENT MODEL FOR THE LABOR MARKET
}

\author{
PABLO DE GRANDE \\ Instituto de Integración del Saber \\ Universidad Católica Argentina \\ Buenos Aires, Argentina \\ pablodg@softhome.net \\ MANUEL EGUIA \\ Centro de Estudios e Investigaciones \\ Universidad Nacional de Quilmes \\ Bernal, Buenos Aires, Argentina \\ meguia@unq.edu.ar
}

\begin{abstract}
We present a multi-agent system where typical labor market mechanisms emerge. Based on a few simple rules, our model allows for different interpretative paradigms to be represented and for different scenarios to be tried out. We thoroughly explore the space of possible strategies both for those unemployed and for companies and analyze the trade-off between these strategies regarding global social and economical indicators.
\end{abstract}

Keywords: Multiagent model; labor market.

\section{Introduction}

Agent-based social simulation has grown rapidly over the last decade, both as an approach to the understanding of social processes and as a technique for creating tools to assist policy formation and evaluation. A clear purpose and an accurate level of complexity is crucial in order to obtain social meaningful concepts. Very often, models are intended to mimic a particular behavior for a parameter set obtained from real observations or fitted from the accessible social measures, or even to "explain" a particular emergent property from simple interacting rules.

However, in order to build confidence upon a particular model or to investigate alternative scenarios, an exploration of several alternative configurations of the multi-agent system (MAS) must be made. This is extremely difficult for the vast majority of the cases, due to the inherent complexity of these models. Nevertheless, one can take some prototypical behaviors or strategies from the model, and assuming that they can give rise to the observed global behaviors, its parameter space can be explored. 
In this work we present a MAS for the labor market, define a strategy space where, at a zero-order approximation, the main dynamics take place, and test a set of working hypothesis that are relevant for social studies in this field.

A number of multi-agent systems were proposed in order to explore the dynamic of markets towards an equilibrium based on local (decentralized) bargaining exchange (see Ref. 1 and references therein). In recent years, many models also began to explore different features of labor markets: migration decisions, ${ }^{2,3}$ the matching process, ${ }^{4-6}$ the impact of different job capacities and job concentrations, ${ }^{7,8}$ as well as the role of contacts and social networks. ${ }^{6,9}$ In this paper we will explore a MAS focused on the strategy of companies and employees, regarding salary and labor participation, stressing the importance of the dynamics of the households and the behavior of the agents during unemployment (represented by the evolution of expectation and duration of the job search).

An outline of the paper follows. In Sec. 2, we present the problem under study, highlighting the topics we are interested in, reviewing classical and previous approaches to the subject and making explicit our working hypothesis. In Sec. 3, we describe the model in detail, referring the assumptions made in the design of the multi-agent system and defining the strategy space. In the following section, we present the results of our strategy space exploration and we analyze the time evolution and correlation between some global magnitudes in the light of our hypothesis. Finally, in Sec. 5 we summarize our conclusions.

\section{Statement of the Problem}

The nature of unemployment has long been a controversial matter. Neoclassical theory characterizes unemployment either as frictional (as a temporary state until everyone can get a job), voluntary (meaning that people overestimate their own value in the market) or as a product of policies that prevent the market from finding its equilibrium. Keynes followers, rather than to suspend policies that disrupt the action of the invisible hand, intend to devise adequate policies and regulations to reduce the effect of cyclical behavior of the economies that could cause periods of high levels of unemployment. Institutionalists, like Polanyi and Piore, ${ }^{10}$ account for the analysis of the labor market as a social institution, where regulations, segmentation and specific mechanisms prevent a supply and demand approach from being effective. The Marxian theory proposes that unemployment acts as a reserve army, that is available for all cases in which additional workers are required, keeping at the same time wages as low as possible. Lastly, the Nun thesis about long-term unemployment, for the case of Argentina, suggests that there may be a marginal mass of people that is unnecessary for the economic system and that will actually never be reemployed. ${ }^{11}$

Solely the participation into the labor market can itself be considered a subject of study, as its variations usually assume ambiguous interpretations. The concept of participation in labor markets "measured as the rate of activity, or rate of 
participation" relates to the decisions people make about to work or not to work. First of all, children and aged people are assumed not to participate in the labor market in most of the cases. Secondly, people considered adults can have a variety of occupations that may keep them outside the labor market (studying, child caring, etc). As information available is usually weak (partial), it becomes difficult to answer all or many of the following questions: Which persons from the population decide not to look for a job because they believe they will not find one? (This is named inactivity by discouragement, and a kind of hidden unemployment.) Or are those cases the result of intentional choices of life courses that traverse periods outside the labor market? And, does an increment on the rate activity evidence a higher attraction to available jobs? Or is that activity increment a reaction facing income shortage?

Moreover, participants in the labor market are coupled in different ways. Unions, trusts, local and sector regulations impose specific overlapping non-homogeneous restrictions, while supply takes its individual decisions mediated by their family strategies and household characteristics.

There are two assumptions of sociodemographic and economic theory that shape our model:

(1) Regulations on unemployment are strongly coupled to changes in wages and companies' profit.

(2) Households as collective actors mediate the individual decisions on labor participation in the form of family strategies.

It is worth noting that we refer to strategies as an analytical way to organize the actions of the interactive agents of the model, i.e., we do not assume that the actors themselves strategically plan their courses of action nor choose by their will, nor always have different options on all possible paths. In the case of real households, quite often decisions about participating or not in the labor market are guided by necessity, or by long term projects, rather than a selection of strategic moves to maximize overall or local game utility. In the case of companies, dismissals can also appear in the domain of necessity, thus restricting the way the concept of strategy should be considered (as actors react based on short-term information criteria).

There is a particular role given to seniority within the model. Defined as the length of an employee's continuous service in an organization, ${ }^{12}$ seniority in the model is bounded to an obligation for every employer to pay an additional amount of money as a function of how many years the employee has been at the company. This obligation can look uncommon for many real labor markets. However, the motivation for this regulation is to represent the influence of any of the following three elements:

(1) "Seniority systems", which exists in different countries, usually in a per-union basis, that ensures higher benefits for older employees (more days for vacation, sick days, augmentation of the salary). ${ }^{12}$ 
(2) When costs associated to seniority do not exists, it can still be forbidden to companies to lower salaries for current employees. Thus, if salaries cannot decrease over time, and some of them may rise, they will, on average, augment.

(3) Even for steady salaries, the rate of profit for the companies can decrease for many different reasons (e.g., obsolescence of existing products and plants, an increase in constant versus variable capital ratio, market saturation). Having an increase of salaries by seniority introduces a pretty realistic adversity for the companies, among many others that require cost reductions.

The hypothesis that will be tested are the following:

H1. Relative market power. Unemployment increases relative market power over the labor force, and when the labor market shows a higher turnover rate, companies' profit grows.

H2. Decisions on unemployment. Even when the decision of firing people is an attribute of the employer, turnover's effect on labor cost are dependent on the capacity of the unemployed people to stay looking for similar conditions for reentrance.

H3. Strategies in labor market. Labor market cannot be analyzed as a zero sum game. It is not the case that every action that makes a player to maximize its welfare jeopardizes the other player's welfare. There are conditions where both players (companies and employees) need to coordinate to stay in a region of the strategy space suitable for both of them.

H4. Salary and wage. Higher salaries can reduce the chances for companies to survive, reducing the chances for all households to assure a minimal wage, thus causing inequality over population.

H5. Discouragement. The amount of time people can dedicate to look for a job before they get discouraged has a major impact on wages.

The present work shows the current progress we have attained on the construction of a multi-agent model in order to test these hypothesis. Some remarkable features and limitations of our model are:

(a) We do not recreate labor market links with other markets, such as goods market and capital markets. The fact that only endogenously determined issues are included in the model implies limitations. For example, it is not possible to control the the impact of higher wages on internal consumption, or whether lower salaries or more flexible conditions would attract global investors.

(b) As productivity is fixed, the model does not account for employees whose seniority comes with higher productivity, or positive effects on higher salaries or disciplinary effects of unemployment over workers' productivity.

(c) The matching function defined for the model is extremely simple. It only represents the fact that a job search can fail at a random rate. 
(d) No bargaining. When a company and a firm match, the company has enough information to make sure it will never pay more than the employees' reservation salary.

(e) Workers do not abandon their jobs once they have one. They do not age nor migrate.

(f) Strategies for employees and employers are homogeneous. For real markets, segmentation and higher levels of heterogeneity could be expected and should be modeled.

(g) Agents do not have spatial coordinates and there is no distance between them.

(h) The smallest time scale (and timestep) for the model is one month.

Our model recreates the labor market of an imaginary small town named Luis Casares del Monte with some characteristics inspired by a previous field research by De Grande in the periphery of Buenos Aires. In what follows we often refer to our MAS as the Casares model.

\section{The Model}

A description of the Casares model follows.

There are two types of actors: employees (workers) and companies. Both employees and companies are characterized by one out of five possible tags (symbolized by a color) that represents a particular specialization in the labor market.

Employees have two attributes regarding their employment and household situation. From the point of view of the participation in the labor market, a person can be in three different states: (a) employed, (b) unemployed and looking for a job, and (c) inactive, that is, people that do not have nor seek to have a job. Employees belong to a company with a matching tag and are further characterized by their salary $s_{i}$ and seniority $a_{i}$ (number of months since they started at the current job).

The household structure in this formulation of the model is defined by the number of potentially active members that each family has, and this is reduced to one or two family members. Only people living with an employed partner can become inactive. People living alone are compelled to look for a job for his/her own subsistence. There are 5000 people (1000 of each color tag) able to work in Casares and this value is fixed through the simulation. They are grouped randomly to form 2000 couples and 1000 single persons.

Companies, on the other hand, can engage a maximum of 100 employees and all attain a fixed revenue per employee (the employee productivity $P$ is fixed). The salary for the $i$ th employee $\left(s_{i}\right)$ of the company is calculated from the initial salary value plus a fixed annual salary increase rate $S_{I}$.

If the salary mass $S$ that the company is obliged to pay exceeds the total income, then the company goes to bankruptcy. This means that companies can survive only if: 


$$
\sum_{i}^{N_{E}}\left(P-s_{i}\right) \geq 0,
$$

where the sum is over all the $N_{E}$ employees of that company. The Gross Product $G_{P}$ of the company is simply $G_{P}=P N_{E}$, and the profit is: $G_{N}=G_{P}-S$. The smaller the relative profit $G_{N} / G_{P}$, the greater the risk of going into bankruptcy.

There are a maximum of ten companies for each of the five color tags. If some company crashes, a new company of the same tag can be created after some fixed time $R$ (recovering time).

There are two mechanisms that operate the strategies implemented by the unemployed people on one side and the companies on the other: the job search process and the periodic dismissals of employees, respectively.

The job search process takes the following steps: after a dismissal or a company crash, people become unemployed and start to look for a job (or, in the case that the agent has a working partner she/he can become inactive with probability 1/2). At first, they expect a salary equal to their last paid salary $s_{l}$. They consider this expectation as their reservation salary, i.e., they will not go for any job paying less than such expectations. Each unemployed agent chooses a company having a position available at random, disregarding its color. If there is a color mismatch between the agent and the company the candidate does not qualify for the position and is rejected. If the colors match then the agent becomes employed in that company with a salary equal to her/his expectation. Rejected agents decrease their expectation $E$ at a fixed monthly rate $D_{1}$, and persist in the search for a job. This decrease in expectations represents the time effect over the search that cause the agent to accept worse conditions as far as this leads him/her to a job. Now, two different situations can arise:

(a) The salary expectation can decrease too much, reaching a minimum allowable salary expectation $s_{\text {min }}$. In that case the salary expectation remains in this value.

(b) If the unemployed agent has a spouse who has a job, he/she abandons the job search after $D_{2}$ months and becomes inactive.

The expectation after $t$ months since the job search started can be expressed more formally as:

$$
E(t)=\Theta\left(\frac{s_{l}-s_{\min }}{D_{1}}-t\right)\left(s_{l}-D_{1} t\right)+\Theta\left(t-\frac{s_{l}-s_{\min }}{D_{1}}\right) s_{\min },
$$

where $\Theta$ is the Heaviside step function and $s_{l}$ is the last salary received. This equation applies with the same parameters to all the unemployed agents. This means that the job search strategy is homogeneous through the model.

Salaries of the employed agents rise with a fixed annual rate $S_{I}$ and cannot be decreased. Since the productivity is fixed, there is a conflict between firms that want to keep their profit $G_{N}$ over zero and employees that want to get its seniority 
rewarded. The only regulation mechanism left to the employer is the possibility of dismissing some employees periodically if he/she considers that there is a risky situation.

The strategies for dismissals are also homogeneous for all the companies, and work as follows: Every December, all the companies calculate the profit over the past year and decide, based on their common strategy, which fraction of the employees will be fired during the next year. Dismissals appear to the companies as a way to reduce the salary mass $S$, as unemployment usually comes with a fall of expectations.

The employer strategy is characterized by three parameters: $F_{1}$ denotes the maximum dismissal rate attainable when the company is about to crash (the profit is zero), $F_{2}$ is the maximum profit balance, averaged over the past year, that the company considers "risky" and still decides to fire some employees. With these two values we define a linear relation between the dismissal rate $F$ and the profit $G_{N}$ :

$$
F\left(G_{N}\right)=\Theta\left(\frac{G_{N}}{G_{P}}-F_{2}\right)\left(F_{1}-\frac{F_{1} G_{N}}{F_{2} G_{P}}\right) .
$$

Finally, the parameter $F_{3}$ measures the periods in which the dismissals will be implemented during the next year. The fired employees are drawn from the company at random and do not receive any compensation.

We will make use of the following global observables in our model: average salary over the employed agents $S$, unemployment rate $U$, activity rate $A$, total gross product $G_{P}$, profit $G_{N}$, number of open companies $M_{C}$, average wage over the population $W$, and average wage per household $W_{H}$.

Some magnitudes are deduced directly from the state of the multi-agent model. At each timestep there are $N_{e}$ employed agents receiving a salary from $\left\{s_{i}\right\}, i=$ $1 \cdots N_{e}, N_{u}$ unemployed agents, and $N_{i}=N-N_{e}-N_{u}$ inactive. There are also $M_{c}$ companies with $\left\{N_{E}^{(j)}\right\}, j=1 \cdots M_{c}$ employees and a profit calculated from Eq. (1). Since in social studies we are more familiar with percent measures in what follows, we will make use of relative percent rates such as the activity rate $A=100\left(N_{e}+N_{u}\right) / N$ or the unemployment rate $U=100 N_{u} / N_{a}$ (which is calculated over the active population).

The calculation of the other global quantities is straightforward. The total gross product is simply $G_{P}=P N_{e}$ and the total profit is $G_{N}=N_{e}(P-S)$, where $S$ is the average salary:

$$
S=\frac{1}{N_{e}} \sum_{i=1}^{N_{e}} S_{i}
$$

The parameters that define the strategy space of the unemployed/employed agents and the companies that will be explored in this work are: $D_{1}, D_{2}, F_{1}, F_{2}$, and $F_{3}$. All the other parameters are fixed at the following values:

- Companies can be created six months after a company crash using the same color: $R=6$. 
- The annual salary rise is fixed at six percent $S_{I}=0.06$.

- People preserve their marital and household status, so the population $(N=5000)$ and number of couples $\left(N_{c}=2000\right)$ is preserved. The productivity is fixed at an arbitrary value of 20 "credits" (the currency of Casares) and the companies are bounded by a maximum of ten companies for each of the five colors $\left(M_{c} \leq 50\right)$ and all have up to one hundred of labor positions. Therefore, a scenario with full employment can be eventually attained.

\section{Simulation and Results}

We started our simulation from an arbitrary initial condition, by assigning a random company of a matching color. Salary is fixed at ten credits and an average of seniority of 12 years with a standard deviation of five years.

After some preliminary exploration of the five-dimensional strategy space $\left(D_{1}, D_{2}, F_{1}, F_{2}, F_{3}\right)$ we found that the subspace $F_{1}=F_{2}$ is representative enough of $\left(F_{1}, F_{2}\right)$. Furthermore, for the purpose of testing our working hypothesis, the parameter $F_{3}$ has no crucial impact on the dynamics. Hence, in what follows, we will explore the three-dimensional strategy space $\left(D_{1}, D_{2}, F\right)$ where $F=F_{1}\left(=F_{2}\right)$ is the only control parameter of the strategy for the companies, and $F_{3}=1$ (all dismissals take place once in a year).

We also observed that, after some relaxation time (that depends on the initial conditions) all the realizations of the system reach a stationary state with either well-defined bounds for the observable quantities or some bounded oscillations having defined characteristic times. The relaxation to the stationary state from the initial conditions stated above takes place after 120 months, approximately. This is the time necessary to reach the situation where seniority becomes a major problem for the subsistence of the companies. Therefore, we ran our simulations through 30 years of the history of Casares (360 timesteps), in order to obtain an accurate picture of the stationary state.

The strategy space $\left(D_{1}, D_{2}, F\right)$ has a real sense in the definite positive octant and it was explored inside realistic bounds $\left(D_{1} \leq 0.5, D_{2} \leq 25\right.$ and $\left.F \leq 0.8\right)$, using different grid intervals. A typical exploration using $10^{4}$ grid points takes up to 20 hours in a Pentium IV machine using a simple Python implementation. ${ }^{\text {a }}$

By exploring our strategy space we were able to identify different scenarios that could be mapped with observed labor market behaviors and are relevant for testing the hypothesis outlined in the Introduction.

In the following, we reduce our exploration to some prototypical and quite representative regions of parameter space in our model and display some plots of the time evolution and mutual dependence of the chosen quantitative observables. For the sake of simplicity we will illustrate six basic strategies as a cross combination of three job searching strategies and two very basic company strategies.

aThe source code can be found at Sourceforge.net, under the name of Casares. 
The three agent strategies are termed high, moderate and low expectations and they refer to a slow $\left(D_{1}=0.001\right)$, intermediate $\left(D_{1}=0.01\right)$ and fast $\left(D_{1}=0.1\right)$ order of magnitude decrease of the salary expectations, respectively. We also take three possible values of the discouraging time parameter $F_{2}$ : from one months to 25 month in steps of 12 . The two company strategies are: (a) few dismissals: use the dismissals only if necessary and very gently: $F=0.01$; (b) many dismissals: make a wide use of the dismissals: $F=0.5$.

In Fig. 1 we plot the time evolution of the percent unemployment rate $U$ (averaged for each year), spanning 30 years of Casares history. One can clearly notice the transient behavior from a low unemployment (initial condition) to a collapse at the end of the first decade. This collapse can either evolve to a permanent crisis or be resolved depending on the strategy implemented. Here the role played by the salary expectation parameter $D_{1}$ is quite remarkable. For high expectation values (continuous line), the system goes through a severe crisis and never recovers again, no matter which strategy of dismissals is implemented. This corresponds to a scenario where the population commits itself to honor their last salary and only decreases its expectations in small steps. The high level of unemployment is the counterpart of many companies going continually into bankruptcy. Under this situation, a high turnover on the labor market (i.e., the effects of many dismissals) does not have a

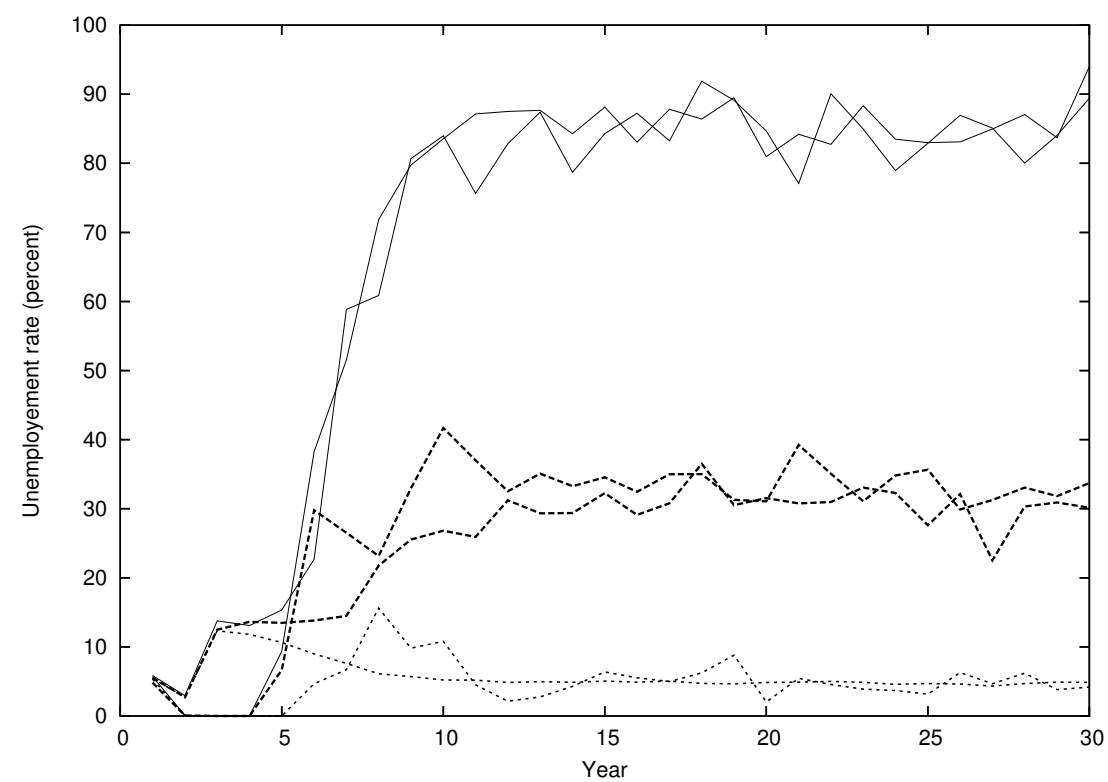

Fig. 1. Time evolution of the percent unemployment rate $U$, averaged over one year, for 360 timesteps (30 years). We display the evolution of the system under the six combinations of strategies defined by $D_{1}$ and $F=0.01$ and 0.5 . The solid lines correspond to job strategies defined in the text as high expectation $D_{1}=0.001$ (for both few and many dismissals), dashed lines to moderate expectation $\left(D_{1}=0.01\right)$, and dotted lines to low salary expectation $\left(D_{1}=0.1\right)$. The discouragment parameter $D_{2}$ is fixed at 13 months. 
positive effects on the health of the companies, and Casares stay in a continuous economic crisis.

In the case of moderate and low salary expectations, the system is more sensitive to the dismissal strategy. However, by taking the annual unemployment average, this value seems to depend on the unemployed strategy only. This indicates that, under an equilibrium situation, the system recovers very fast from the annual dismissals and attains an unemployment rate that basically reflects the turnover rate. While for a moderate salary expectation (dashed lines) the unemployment rate stabilizes close to $30 \%$. Low salary expectations (fast decrease of the expected salary) keep average unemployment rate below ten percent (dotted lines).

In Fig. 2, we show the time evolution of another quantity of interest: the average salary over the employed population $S$. In this figure one can see the side-effect of a low unemployment rate and the impact of a strategy of massive dismissals. In the inflexible scenario of high expectation values $\left(D_{1}=0.001\right.$, solid lines), we have very few agents receiving the maximum salary (20 credits) and as the expectation is lowered, the average salary gently decreases. Note, for example, that by lowering the expectation to an intermediate value $\left(D_{1}=0.01\right.$, dotted lines) we have a reasonable bounded unemployment rate, lowering the average salary by only one credit (5\%). However, if we try to lower further the turnover and unemployment rates by lowering the salary expectation $\left(D_{1}=0.1\right)$ the decreasing of the average salary is apparent. Also, for the lower expectation we observe a strong impact of

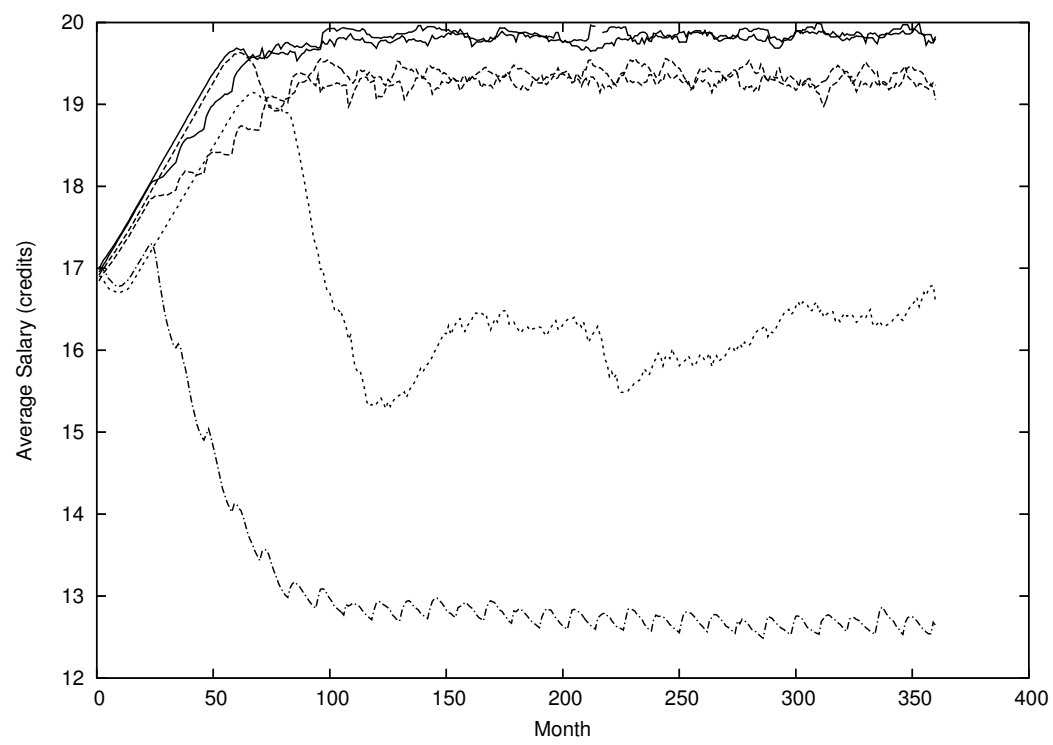

Fig. 2. Time evolution of the average salary with monthly resolution. We use the same line scheme as in Fig. 1 for high and moderate expectations, but we further differentiate low salary expectations in combination with few dismissals (dotted line) and many dismissals (dot-dashed line). 
the employer strategy. While for a few dismissals policy $(F=0.01$, dotted line $)$ the average salary oscillates between 15 and 17 credits, for a tighter policy of many dismissals $(F=0.5$, dash-dotted line) the average salary goes below 13 credits.

Let us now compare pairs of observable quantities after the stationary state is established. We will average our measures over 200 months after the 160th month, for each run.

The activity rate $A$ is plotted against the unemployment rate in Fig. 3. An expected one-to-one correspondence between the activity rate and the discouragement parameter $D_{2}$ is displayed. Note that while for low expectations, both employer and discouragement strategies have no impact, in the cases of moderate expectations, the unemployment rate shows a high sensitivity to discouragement (with an impact on unemployment ranging values from 20 to 35 ).

In Fig. 4, we display the dependence between wage (income of the employees averaged over the population) and the global profit. This plot clearly reflects the trade-off between the strategies of the agents and the companies. One can observe also the variety of income that the potentially active population receives under different strategies. This can be seen, regarding the employee strategies, as the cost of each strategy from the standpoint of households (and as a map of the income distribution). At the same time, the plot provides a map of each strategy according to winning and losing players. All strategies that are close to the bottom are losing

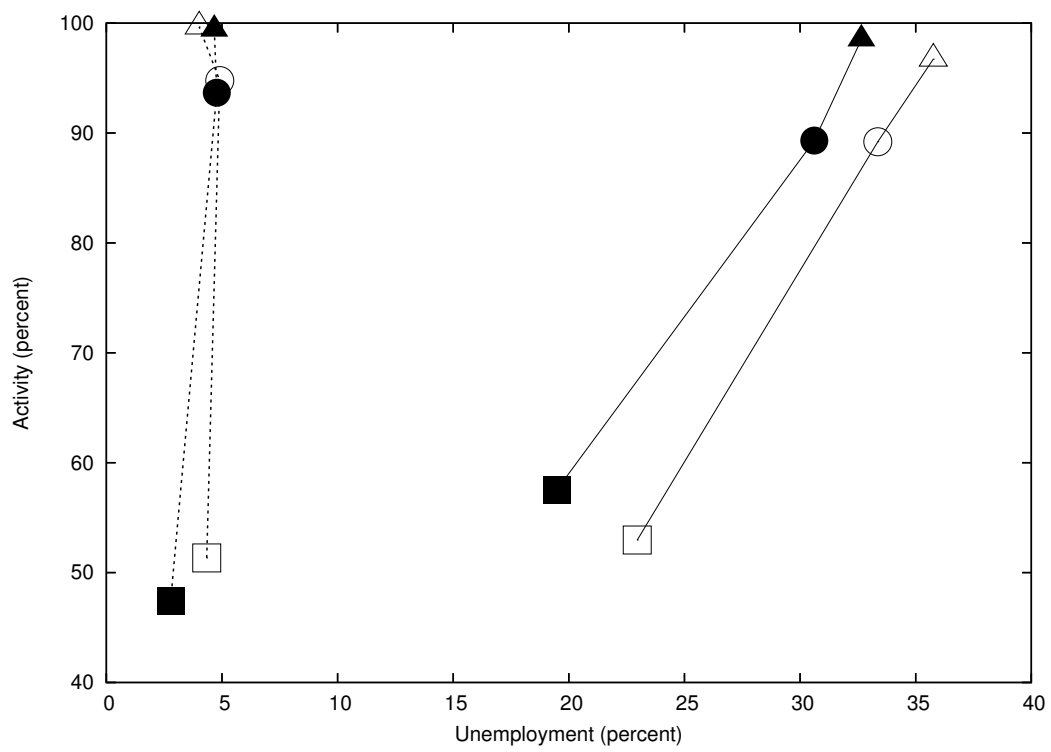

Fig. 3. Percent activity rate as a function of unemployment rate for the average of 200 months of stationary behavior. For companies, solid symbols correspond to strategies with few dismissals, and hollow symbols to strategies with many dismissals. For employees, moderate expectations are shown as solid lines, and low expectations as dotted lines. Squares, circles and triangles represent one month, 13 months and 25 months for discouragement. 


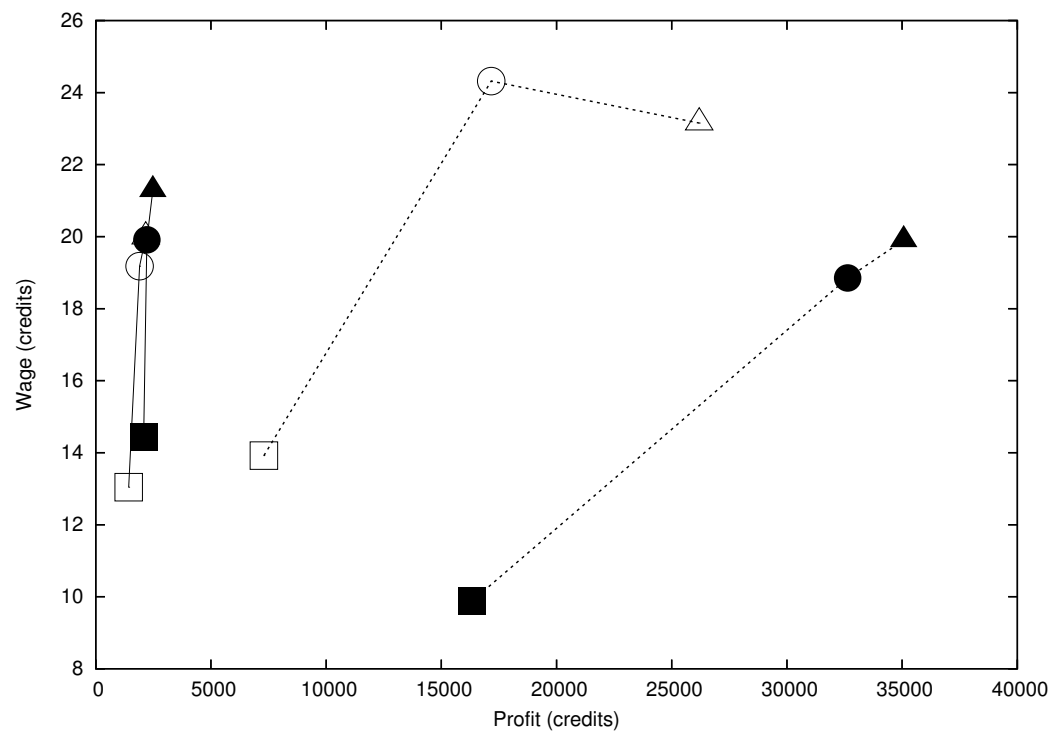

Fig. 4. Average wage as a function of global profit with the same time interval as in Fig. 3 and with the same symbols.

strategies for the households, while strategies close to the left are losing strategies for the companies.

H3 can be supported by this plot, by the fact that under low expectations, extending the time in searching for a job shows positive results for both sides (higher profit and higher wages). However, when there are few dismissals (hollow shapes and dashed line) increasing the search period beyond 13 months turns the relation into a zero sum game. As it produces more profit with more effort in the search, the wage of the population lessens. The exploration of the strategy space leads us to present in this plot two configurations for which unions and firms could struggle: both scenarios of low expectations - with many or few dismissals — seem possible, i.e., the future state for the Casares village only can be determined by the ability of each actor to negotiate and influence over regulations around these key elements:

(a) support to extend time for searching jobs;

(b) flexibility of expectations (minimal salaries regulations); and

(c) number of socially acceptable dismissals.

H5 (impact of discouragement on wages) can be seen, with reduced effects in the case of moderate expectations. In the case of low expectations, a nonlinear relation between discouragement and wage can be observed.

Our last plot in Fig. 5 exhibits the values of the average wage $W$ as a function of the average salary $S$. For each of the employees strategies, the effects of the corresponding company strategy into salaries and wage are shown. The $D_{2}$ parameter 


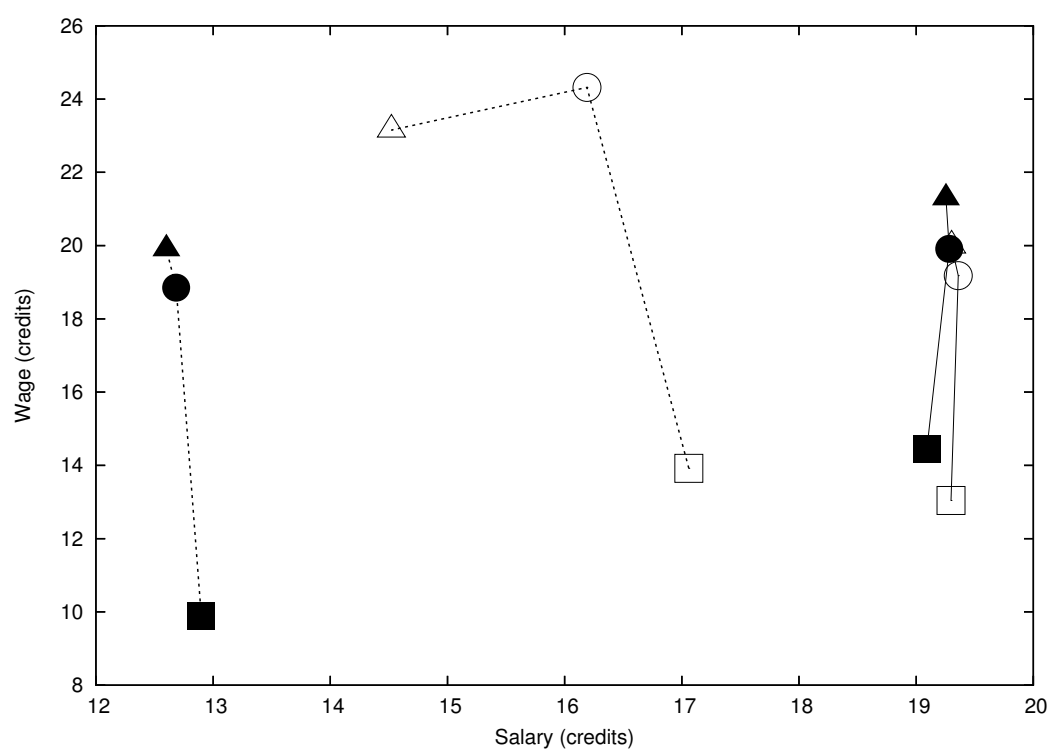

Fig. 5. Wage as a function of the average salary of employed agents with the same time interval than Fig. 3 and the same symbols.

causes a vertical dispersion of the points, while more severe dismissal policies reduce average salaries in 0.2 to 2.4 credits depending on the employees' strategies. It is also worth noting that the situation of privileged employees (high inequality) can be seen when expectations are moderate: while the average income per household takes values as low as 13 credits, the average salary of those who are employed is above 19 credits.

These inequalities confirms $\mathrm{H} 4$ and challenges $\mathrm{H} 3$, as not only the labor market can be seen as a nonzero-sum game, but initially homogeneous workers - presumed to be able to act as collective actors - can run into strategies that ensures high salaries for some of them but low wages for the whole population (i.e., if a heterogeneous strategy would be allowed in the model, and only a few persons could stand for high expectations and long term search, inequalities would be even larger).

Examining salary in regard of H2, the ability of the population to keep searching for a job under unemployment correlates with average salary in a positive way under moderate expectations (this situation is sometimes called "selective search" or "voluntary unemployment"). Under low expectations (with deterioration of the working conditions compared to the previous job) they correlate in a negative manner.

With respect to H1, more dismissals positively correlates with lower salaries. However, this effect almost disappears when employees manage to stay in moderate expectations. To evaluate turnover, we will analyze situations with similar activity and unemployment rates but different strategies of dismissals. Looking at Figs. $3-5$ together the situation of salary related to profit and unemployment can be spotted. 
Maximum profit is reached with low unemployment (Figs. 3 and 4), when salaries are at an average of 13 credits (Fig. 5), their minimum value.

\section{Conclusion}

The Casares model worked as a minimal synthetic implementation of family decisions and salary fluctuations. These were two key factors in previous field research that we made, and their main observed macrodynamics has been successfully simulated.

From the standpoint of family strategies, the model provides rich data to profile the dominant strategies at each scenario, and allow for future incorporation and exploration of non homogeneous adaptative family strategies.

The model shows different sensitivity to each strategy of the companies depending on the strategies of the employees. This feature is of great interest, given that employees and companies build their strategy with no knowledge of the other part's decisions.

Regarding initial hypothesis, the following conclusions from the model can be drawn:

- H1. Relative market power. Market power shows an ambiguous result. When employees are able to keep their expectations decay in a moderate level (decreases monthly by $1 \%$ ), the capacity of the companies to control the market gets compromised. On the other hand, when the expectations (or reservation salary) lessens at $10 \%$ every month during unemployment, the policy regarding annual dismissals has a strong impact on average salaries. At the same time that salaries decrease, profit grows accordingly.

- H2. Decisions on unemployment. As stated below, the consequences of continually looking for a job depends on the conditions of the job search. For more than 13 months, the effect is negative in average salaries, and under low expectations it can even be negative in wages (as seen in Fig. 5).

- H3. Strategies in labor market. The labor market under these simple rules had shown complex strategic situations. For certain parameters (strategies) the model becomes a zero-sum game. For others, a space for cooperation remains open. In the analysis of inequality, we had pointed out that prisoner-dilemma-like situations appeared (defeat was represented by workers with higher salaries than the global product could allow without creating significant inequality).

- H4. Salary and wage. The relation between salary and wage revealed a sort of game inside the game, considering the payoff matrix among employees according to each strategy.

- H5. Discouragement. Discouragement had a strong effect on most outputs of the model. Remarkably, it show a nonlinear relation with wage and salary, and its effects where amplified or diminished by the strategy of the companies. 
We are enthusiastic about further study on "acceptable conditions" (expectations, or reservation wage) analysis. The implication of reliable work on this topic, from field observations to representation into models, may have a major impact on the way search processes and employability are evaluated. The impact in the population of long-term unemployment and high turnover rates should not be underestimated in complexity, as its regulatory effects probably supass the metaphor of "reserve army".

We released the source code of the project to allow further variations of the model. These extensions could include features such as more complex search algorithms, larger population size, explorations of different regimes of dismissals, cognitional representations of the agent.

The model, as said before, was build with no predictive goals. For future work, we envision the possibility of this experience as a step into the path of exercising the fit of parameters and main mechanisms of empirical data series into a multi-agent simulation model.

\section{References}

1. J. M. Epstein and R. Axtell, Growing Artificial Societies: Social Science from the Bottom Up, Chap. 5 (MIT Press, Camdridge, 1996).

2. A. L. Espindola, T. J. P. Penna and J. J. Silveira, Int. J. Mod. Phys. C 16(12) (2005).

3. C. Detang-Dessendre, C. Drapier and H. Jayet, J. Regional Sci. 44, 661 (2004).

4. A. Chaturvedi, S. Mehta, D. Dolk and R. Ayer, European J. Operational Research 166, 694 (2005).

5. M. Neugart, Labor market policy evaluation with ACE, Agent-Based Models for Economic Policy Design (ACEPOL05).

6. G. Ballot, J. Economic Behavior Organization 49, 51 (2002).

7. L. Tesfatsion, J. Economic Dynamics Control 25, 419 (2001).

8. S.-R. Yang, J.-K. Min and S.-B. Cho, Agent-based evolutionary labor market model with strategic coalition, Australian Conference on Artificial Intelligence (2004).

9. A. Calvo-Armengol and M. O. Jackson, 2003 Am. Econ. Rev. 94, 426 (2004).

10. M. J. Piore, Notas para una teoría de la estratificación del mercado de trabajo, El Mercado de Trabajo: Teorías y Aplicaciones, ed. L. Toharia (Alianza Editorial). [English version: Notes for a theory of labor market stratification, eds. R. C. Edwards, M. Reiche and D. M. Gordon, Labor Market Segmentation (Lexington Books, Lexington, 1975).

11. J. Nun, El futuro del empleo y la tesis de la masa marginal, in Desarrollo Económico, 38(152) (1999); English translation: Latin American Perspectives (California) 7, 6 (2000); Novos Estudos CEBRAP (Sao Paulo) 56, 43 (2000).

12. M. E. Gordon and W. A. Johnson, Personnel Psychology 35, 55 (1982). 